\title{
Corrigendum: The Effect of Micro-Spicule Containing Epidermal Growth Factor on Periocular Wrinkles
}

Jeong-Min Ha, Cho-Ah Lim, Kyuboem Han ${ }^{1}$, Jong-Cheon $\mathrm{Ha}^{1}$, Hae-Eul Lee, Young Lee, Young-Joon Seo, Chang-Deok Kim, Jeung-Hoon Lee, Myung Im

Department of Dermatology, Chungnam National University School of Medicine, ${ }^{1}$ Paean Biotechnology Inc., Daejeon, Korea

Ann Dermatol 2017;29(2):187-193

https://doi.org/10.5021/ad.2017.29.2.187

The authors note that the units on page 188 were reported incorrectly.

At the first line of the MATERIALS AND METHODS section in the text and the legends of Fig. 1, "0.25- $\mu \mathrm{m}$ " should be replaced by "0.25-mm."

The authors apologize for these errors.

This is an Open Access article distributed under the terms of the Creative Commons Attribution Non-Commercial License (http://creativecommons.org/ licenses/by-nc/4.0) which permits unrestricted non-commercial use, distribution, and reproduction in any medium, provided the original work is properly cited.

Copyright $($ The Korean Dermatological Association and The Korean Society for Investigative Dermatology 